\title{
A Visão do Idoso Sobre o Seu Processo de Envelhecimento
}

\author{
José Nilson Rodrigues de Menezes ${ }^{1}$, Monique de Paula Monte Costa ${ }^{2}$ \\ Ana Celina do Nascimento Silva Iwata ${ }^{3}$, Priscila Mota de Araujo ${ }^{4}$ \\ Liliana Gama Oliveira ${ }^{5}$, Cleidiane Gonzaga Damasceno de Souza ${ }^{6}$ \\ Paulo Henrique Palácio Duarte Fernandes ${ }^{7}$
}

\begin{abstract}
RESUMO
Objetivo: Analisar a visão do idoso sobre o seu próprio processo de envelhecimento. Matérias e Métodos: Tratou-se de uma pesquisa descritiva, com abordagem qualitativa, realizada no Núcleo de Atenção Médica Integrada (Nami) da Universidade de Fortaleza, localizado na Rua Desembargador Floriano Benevides, 221, no Bairro Edson Queiroz. Participaram da pesquisa 20 idosos de ambos os sexos, com idade a partir de 60 anos, que receberam assistência fisioterápica no Núcleo de Atenção Médica Integrada no período de fevereiro a março de 2016. As informações foram colhidas por meio de uma entrevista semiestruturada, gravada e transcrita na íntegra, em uma sala reservada. Resultados: Após transcrição, leitura e releitura das entrevistas, surgiram as seguintes categorias de análise: o estar idoso na sociedade, convivendo com as alterações físicas inevitáveis e a aceitação da velhice, percebendo, por meio das falas, que o idoso hoje está mais participativo, informado e consciente quanto ao seu processo de envelhecimento. Percebe-se, contudo, também, um certo conformismo sobre o estar idoso, porém nada que venha a interferir amplamente em seu envelhecer. Considerações finais: Identifica-se atualmente uma resposta positiva em relação ao envelhecimento. A aceitação da idade por intermédio da conscientização sobre o processo de envelhecer, principalmente em relação às alterações físicas, faz com que os idosos não se abstenham de suas atividades diárias, tampouco do convívio social, tornando-os assim, mais felizes nessa fase da vida.
\end{abstract}

Palavras-chave: Fisioterapia. Idoso. Envelhecimento.

\section{THE VISION OF THE ELDERLY ON YOUR AGING PROCESS}

\section{ABSTRACT}

Objective: Analyzing the elder's vision about their own process of aging. Materials and Methods: It was about a descriptive research, with quantitative approach, developed at Nami (Integrated Medical Atenttion Nucleus), from Fortaleza University, located on Desembargador Floriano Benevides street, 221, in Edson Queiroz neighborhood. Twenty elderly people participated from both sex, from 60 years up who had physical therapy at Nami from February to March of 2016. The pieces of information were achieved by semistructured interview, recorded, fully transcribed, in a reserved room. Results: After transcription, reading and rereading the interviews, emerged three following categories: to be old in the society, dieling with the inevitable physical changes and the old age acceptance. Analyzing the comments, It could be noticed that the elders are more participatory and aware about their process of aging. However, it is also noticed, a kind of conformism about to be old, nevertheless, nothing what can intervene widely in their age. Final Considerations: Actually, it can be identifyed a positive response related to aging. The age acceptance by the age process awareness, specially about the physical changes, makes the elderly people not to abstain from their daily activities, nor it is about their socialising, becoming, in this way, much happier in this life stage.

Keywords: Physiotherapy. Old. Aging.

Recebido em: 20/12/2017

Revisões requeridas em: 18/5/2018

Aceito em: $3 / 9 / 2018$

\footnotetext{
Doutor em Biotecnologia pela Universidade Estadual do Ceará (Uece-Renorbio). Professor na Universidade de Fortaleza (Unifor) na Graduação de Fisioterapia e Psicologia e na Pós-Graduação de Neurociência Reabilitação. Centro de Ciência da Saúde - CCS - Fisioterapia.nilson.pesquisa@hotmail.com

2 Fisioterapeuta pela Universidade de Fortaleza (Unifor). Especialista em Fisioterapia Dermato Funcional pela Universidade de Fortaleza (Unifor). Moniquedepaula.mc@gmail.com ${ }^{3}$ Fisioterapeuta pela Universidade de Fortaleza (Unifor). Pós-Graduada em Osteopatia pela Escola Brasileira de Fisioterapia Manipulativa (Ebrafim). ana_celina@hotmail.com

${ }^{4}$ Fisioterapeuta pela Universidade de Fortaleza (Unifor). Pós-Graduanda em Fisioterapia Cardiovascular Ambulatórial e em Uti (Unifor). priscila.maraujo13@gmail.com

Fisioterapeuta pela Universidade de Fortaleza (Unifor). Pós-Graduanda em Fisioterapia Respiratória Cardiovascular Ambulatórial e em Uti (Unifor). lilihannag@hotmail.com

${ }^{6}$ Graduanda em Fisioterapia pela Universidade de Fortaleza. Bolsista do programa de Iniciação Cientifica da Fundação Edson Queiroz (Probic)- Fortaleza-Ce. cleidiane.gonzaga28@yahoo.com.br

Fisioterapeuta pela Universidade de Fortaleza (Unifor). Mestre em Ciências Médicas da Universidade Federal de Fortaleza (UFC). Professor na Universidade de Fortaleza (Unifor). Centro de Ciência da Saúde- CCS-Fisioterapia. ph@unifor.br
} 


\section{INTRODUÇÃO}

Nos últimos anos, modificações demográficas e de saúde tornaram o envelhecimento populacional um fenômeno mundial, atingindo países desenvolvidos e em desenvolvimento, como é o caso do Brasil (MARINHO et al., 2013). Tal crescimento se deve principalmente à relação entre a redução dos índices de natalidade e mortalidade junto ao aumento da expectativa de vida da população em geral (PEREIRA; NOGUEIRA; SILVA, 2015). Além disso, fatores como avanços tecnológicos voltados para a prevenção e cura de doenças, melhorias das situações sanitárias e uma maior conscientização sobre saúde, colaboram veementemente para o aumento dessa população (ORTA, 2014).

O crescimento acelerado da população idosa no Brasil apresenta uma importante questão relacionada com a eficácia da sociedade em se adaptar a esta nova realidade. À medida que a idade de uma pessoa evolui, há alterações psicológicas, biológicas e sociais que requerem cuidados diferenciados (CUNHA; CUNHA; BARBOSA, 2016).

De acordo com a Organização Mundial de Saúde (OMS), para que um indivíduo seja considerado idoso é necessário que o mesmo apresente, no mínimo, a idade de 60 anos em países de terceiro mundo e em desenvolvimento, e de 65 anos para residentes de países de primeiro mundo (CUNHA; CUNHA; BARBOSA, 2016; CAMARGOS; GONZAGA, 2015).

Estima-se que até 2060 esse contingente atinja os $30 \%$. O aumento da expectativa de vida no Brasil tem elevado o número de idosos acima de 60 anos, e este já corresponde a $13,09 \%$ do total da população. Diante desta realidade, torna-se necessário o investimento em pesquisas, modelos assistenciais, formação de profissionais de saúde e em políticas públicas que possibilitem o envelhecimento da população com qualidade (FERREIRA et al., 2017).

Os efeitos do envelhecimento para a sociedade são relevantes, especialmente no que diz respeito à saúde. Com o aumento da velhice, o desafio é viver mais, de forma saudável e com uma melhor qualidade de vida. A impressão das pessoas sobre sua saúde tem resultado importante sobre a saúde e o processo de envelhecimento, sendo referido no estilo de vida. A autopercepção é globalizada e influenciada pela capacidade de o indivíduo responder às demandas da vida cotidiana (MARI et al., 2016).

0 termo envelhecimento pode ser definido como um conjunto de diversas alterações fisiológicas, morfológicas, bioquímicas e emocionais, que não de- vem ser compreendidas isoladamente. Trata-se de um processo progressivo e gradativo de perdas motoras e sensoriais ao longo do tempo, que tornam os indivíduos mais vulneráveis e susceptíveis ao surgimento de doenças que irão afetar diretamente sua funcionalidade (MARINHO et al., 2013; CAMARGOS; GONZAGA, 2015).

O envelhecimento físico ou biológico corresponde a pequenas e imperceptíveis alterações que ocorrem nos organismos vivos ao longo do tempo, causados pela diminuição da dinâmica celular, provenientes do próprio processo de envelhecer (LOBO; SANTOS; GOMES, 2014).

No processo de envelhecimento acontecem diversas mudanças sociais, culturais, econômicas e institucionais no sistema de valores e no desenho dos arranjos familiares, nos quais a mulher era a tradicional cuidadora e está cada vez mais inclusa no mercado de trabalho (BARROS et al., 2016).

A limitação funcional ou capacidade funcional pode ser determinada como a competência do indivíduo de cuidar de si próprio e viver de forma independente, ou seja, manter suas capacidades físicas e mentais em atividades básicas e instrumentais (SIQUEIRA et al., 2017).

A qualidade de vida da população idosa está ligada a elementos que envolvem não apenas aspectos físicos, mas psicológicos e sociais. O bem-estar físico e mental, a inserção social, bem como a produtividade e uma boa estruturação familiar, cooperam fortemente para um envelhecimento saudável (SPOSITO; NERI; YASSUDA, 2016).

O estudo teve como objetivo analisar a visão do idoso sobre o seu próprio processo de envelhecimento.

\section{MATERIAIS E MÉTODOS}

Realizou-se uma pesquisa de natureza descritiva, com abordagem qualitativa, no Núcleo de Atenção Médica Integrada (Nami) da Universidade de Fortaleza, com idosos dos gêneros masculino e feminino que receberam assistência fisioterápica no período de fevereiro a março de 2016.

As informações foram coletadas por meio de uma entrevista semiestruturada, gravada e transcrita na íntegra, em uma sala reservada. Para a gravação utilizou-se o aparelho Android 4.1.

Os dados foram estudados pela análise temáti$\mathrm{ca}$, que consiste em três etapas: pré-análise, exploração do material e tratamento dos resultados obtidos e interpretação (LOPES et al., 2014). 
O presente estudo foi aprovado pelo comitê de ética e pesquisa com parecer $n$ 우 1.325.990.

\section{RESULTADOS E DISCUSSÃO}

Após transcrição, leitura e releitura das entrevistas, surgiram as seguintes categorias de análise: Estar idoso na sociedade, convivendo com as alterações físicas inevitáveis e a aceitação da velhice.

As categorias e as falas dos participantes, neste estudo, passaram por critérios de seleção, nos quais as categorias e as falas possuíram uma relação, exprimindo a opinião da maioria dos participantes da pesquisa.

\section{Estar idoso na sociedade}

O envelhecimento saudável é marcado por medidas como afetos e disposição de espírito e satisfação de vida, e por medidas objetivas, nomeadamente morbidade, mortalidade e independência. A partir de uma perspectiva biomédica, a definição mais relevante descreve-se em três critérios: baixo risco para doenças e alta atividade mental e física, envolvimento ativo na vida cotidiana e deficiências relacionadas à doença (TEIXEIRA et al., 2012).

Envelhecer de forma ativa e ocupar-se com atividades prazerosas favorecem as pessoas longevas a uma vida com mais qualidade. A pessoa deve se envolver espontaneamente com atividades ocupacionais que favoreçam a sua participação social voluntária, bem como a sua capacidade criativa, sejam essas para repousar, divertir-se ou recrear-se (MARI et al., 2016).

... É que antigamente era uma coisa assim pra escanteio o idoso. Nessa idade de 63 anos era pra lá, sai daí véi! Hoje tem até um termo: diz assim oh o coroa! Hoje em dia é mais fácil a comunicação; tem a televisão, as pessoas mais educadas, tem jornal, tem as coisas, então as pessoas já respeita mais um pouco, os direito... (Idoso 2).

... Sou muito bem recebido e bem visto na sociedade, onde eu vivo... Me sinto muito incluído. Sou aposentado, mas a gente procura sempre alguma coisa pra fazer, principalmente a leitura; eu gosto muito de ler; tem a internet, eu gosto de ver alguma coisa; dois jornais por dia eu vejo; tem os noticiários que a gente acompanha; procuro tá sempre muito bem informado... (Idoso 11).

Para esses idosos, a facilidade de comunicação e a agregação de conhecimentos por meio de jornais, televisão e internet, quando o idoso se torna mais informado sobre o que ocorre no mundo hoje, ajudam a tornar a pessoa idosa mais ativa e participativa, o que contribui positivamente para um bom envelhecimento social.

Existe atualmente uma enorme visibilidade da sociedade em relação ao crescimento do número de idosos, trazendo muitas alternativas para inseri-los em diversos ambientes sociais, visando a uma melhor qualidade de vida e o reconhecimento como cidadão (FORON; SANTOS, 2012).

... Na realidade eu acho até melhor está na minha idade, por conta das experiências de vida, mais conhecimento, mais oportunidade de ajudar a quem ainda não chegou na minha idade. Então eu sou muito feliz. Sou aposentada, adoro cantar e agradeço muito a Deus pelo dom de cantar que ele me deu... (Idoso 8).

... Eu vivo muito bem. Sou muito bem aceita onde eu vou, e no meu trabalho todo mundo gosta muito de mim, graças a Deus. Lá as pessoas conversam muito comigo, respeitam e eu me sinto muito ativa. Vivo muito bem. Aonde eu vou sou tratada bem e gosto muito de tá no meio de muitas pessoas... (Idoso 9).

Os idosos entrevistados consideraram a velhice uma fase de experiências e não se sentem excluídos socialmente. Apesar das dificuldades próprias da idade, eles se consideram ativos, bem-aceitos e bem-vistos pela sociedade atual.

\section{Convivendo com as alterações físicas inevitáveis}

O envelhecimento traz várias alterações ao indivíduo, e seu estilo de vida também pode influenciar em sua independência. $O$ processo pode ser natural, quando ligado às alterações fisiológicas e biológicas, ou patológico, quando acompanhado de doenças (ALMEIDA; REIS, 2016).

O processo de envelhecimento contribui para maior vulnerabilidade às doenças, que podem interferir na autonomia, na mobilidade, na destreza manual, na lucidez e na funcionalidade das vias urinárias inferiores e da bexiga, o que favorece a Incontinência Urinária (IU) (MARQUES, 2016).

O processo de envelhecimento possibilita alterações fisiológicas e biológicas no organismo do idoso. O sistema nervoso e musculoesquelético expõe envolvimentos significativos que prejudicam o equilíbrio corporal, o reflexo e a capacidade de deambulação (SANTOS et al., 2016). 
... Eu não gosto de reclamar, porque eu acho que a gente tem que aceitar as coisas da nossa vida. E se aconteceu, foi porque Deus que permitiu. Então eu só não gosto muito de tá doente. Mas eu tento melhorar e levar minha vida bem, graças a Deus. Tirando problema de saúde, o resto tá tudo bem... (Idoso 9).

... Eu tenho problema de saúde sim, mas quem num tem? Tá velho? Então pronto. Tem é que se cuidar. Viveu já muito, curtiu quando era novo e agora a gente num pode parar não. Só porque eu já sou idoso num posso ser feliz? Pois eu sou e muito. E a minha saúde eu cuido muito bem. Então eu só posso dizer que minha saúde vai muito bem obrigado, né não? (Idoso 15)

Geralmente existem algumas perdas cognitivas e físicas relacionadas à fase da velhice, principalmente no tônus muscular, na resistência muscular e na audição, além de possíveis dificuldades na capacidade de memorizar, na atenção e na linguagem. Algumas características e sintomas de algumas doenças não são percebidos pela família do idoso, pois envolvem comportamentos socialmente esperados para a velhice, como apatia, esquecimentos, cansaço, até mesmo ausência de ocupação e isolamento (SPOSITO et al., 2013).

Todos os idosos apresentaram queixas em relação ao seu envelhecimento físico. A diferença, todavia, pode ser percebida no modo como eles percebem a sua própria saúde durante essa fase da vida, deixando claro que, mesmo com tais problemas, procuram levar uma vida feliz, buscando tratamento e uma meIhor qualidade de vida.

A velhice está sendo analisada, hoje, como a fase mais longa do desenvolvimento humano se confrontada ao tempo em que as gerações anteriores viveram e, por isso, compreender como os idosos projetam o futuro para a fase mais tardia de suas vidas é um dos desafios daqueles que trabalham com sujeitos longevos (SANTANA; BERNARDES; MOLINA; 2016).

... A gente vai envelhecendo né e tudo mais, então as coisas vão se desgastando como meu ortopedista diz, né, as articulações. Tô fazendo muita trilha agora, eu tenho uma caminhada anual de $150 \mathrm{~km}$ e tudo mais; caminho todo dia né, então isso aí eu tô bem. Um envelhecimento natural, normal e tudo mais... (Idoso 11).

... Apareceu esse problema no meu joelho, já venho pra cá já faz uns três, quatro ano. Mas tô envelhecendo direitinho. Num, faço nada não. Num caminho, o que eu era pra fazer né, mas eu trabalho, então... só num faço é ficar parado. Num fico parado no fundo da rede não. Trabalho, passeio, tenho uma vida bem ativa. Num tenho do que reclamar não... (Idoso 12).

A conscientização de que o envelhecimento traz consigo o surgimento de doenças, faz com que os idosos se tornem mais ativos e busquem meios para envelhecer de uma maneira mais saudável, mesmo com o fator negativo do desgaste normal causado pelo envelhecimento biológico.

\section{A aceitação da velhice}

Um dos principais fatores que contribui para um envelhecimento saudável está associado diretamente ao conjunto de relações pessoais e influências ambientais em que o idoso está inserido, ou seja, indivíduos que passam exatamente pelas mesmas condições, sejam elas negativas ou positivas, podem apresentar posturas e comportamentos completamente diferentes (SANTOS et al., 2016).

... Me sinto feliz, realizado... Tenho problema nenhum de ser... É aquela história, sempre tem aqueles incomodozinhos da saúde né. Sempre tem problema que a gente vai levando né. Mas é tudo da idade. Sinal que estamos vivos. Não podemos nos entregar a besteiras e coisas ruins não. Temos que viver buscando a felicidade... (Idoso 4)

... Me sinto muito feliz. O que passou, passou e agora é curtir a minha idade. Porque daqui a pouco eu morro e aí? Por isso eu quero é aproveitar o resto dos dia que eu tenho, porque ninguém sabe o dia de amanhã. Então eu acho que minha cabeça é muito boa. Num tenho problema com isso não... (Idoso 15)

Para os idosos entrevistados, sentir-se bem nessa idade é ir levando as dificuldades do dia a dia da melhor forma possível. Eles afirmam estar bem psicologicamente e ligam isso a um conformismo sobre a aceitação de que envelhecer é algo inevitável, não devendo ser visto como impedimento para se tentar ser feliz.

Os déficits cognitivos em um idoso são, muitas vezes, a origem de problemas funcionais, fazendo com que haja dano ou dificuldade para adquirir ou manter as capacidades e habilidades, gerando mudanças de forma geral na sua vida, principalmente nas áreas sociais, econômicas e diárias (MENDES; NOVELLI, 2015).

...Meu psicológico tá muito bem... Não fico reclamando nem me maldizendo o tempo todo como minha irmã fica fazendo. Porque assim... atrai né! Eu faço meu tratamento aqui no Nami pra mim ficar boa e vou levando a minha vida as- 
sim porque envelhecer todo mundo vai. Sou ativa, gosto muito do meu trabalho e isso me ajuda muito... (Idoso 9).

... Eu num tenho esse problema de num gostar de envelhecer não. Minha mente num é sempre ativa não, né. Sempre aparece um problema por causa da idade, um problema de saúde, uma coisa e outra né. Mas é do jeito que Deus quiser. A gente esquece alguma coisa aqui ali, tem o estresse de velho né! Mas mesmo assim me considero bem. Me considero feliz... (Idoso 12).

Pode-se perceber, por meio das falas, que o idoso hoje está mais consciente quanto ao seu processo de envelhecimento. Nota-se contudo, ainda, um certo conformismo sobre o estar idoso, mas nada que venha interferir amplamente em seu envelhecer.

Este estudo apresenta limitações que devem ser consideradas, como número de participantes da pesquisa e por ter sido realizado em uma única instituição e em uma região específica, não abrangendo uma área maior.

Sugere-se a realização de novos estudos dentro dessa temática, abordando aspectos que não foram percebidos ou estudados nesta pesquisa.

\section{CONSIDERAÇÕES FINAIS}

Percebeu-se que o idoso está cada vez mais ativo e participativo na sociedade atual. Identifica-se, hoje, uma resposta positiva em relação ao envelhecimento. A aceitação da idade por meio da conscientização sobre o processo de envelhecer, principalmente em relação às alterações físicas, faz com que os idosos não se abstenham de suas atividades diárias, tampouco do convívio social, tornando-os, assim, mais felizes nessa fase da vida.

\section{REFERÊNCIAS}

ALMEIDA, R. F. F.; REIS, A. O. A. Análise da produção científica no Brasil sobre envelhecimento e quedas. Rbceh, Passo Fundo, v. 2, n. 13, p. 242-253, 2016.

BARROS et al. Capacidade funcional de idosos institucionalizados: revisão integrativa, $A B C S$ Health Sci, v. 41, n. 3, p. 176-180, 2016.

CAMARGOS, M. C. S.; GONZAGA, M. R. Viver mais e meIhor? Estimativas de expectativa de vida saudável para a população brasileira. Cad. Saúde Pública, Rio de Janeiro, v. 7, n. 31, p. 1.460-1.472, 2015.

CUNHA, A. C. N. P.; CUNHA, N. N. P.; BARBOSA, M. T. Geriatric teaching in Brazilian medical schools in 2013 and considerations regarding adjustment to demographic and epidemiological transition. Rev. Assoc. Med. Bras., Belo Horizonte, v. 2, n. 62, p. 179-183, 2016.

FERREIRA, L. V. et al. Busca do autocuidado por idosos na rede de atenção à saúde. Revista Contexto \& Saúde, v. 17, n. 32, p. 46-54, 2017.
FORON, P. M.; SANTOS, P. L. Fatores de risco e proteção associados ao declínio cognitivo no envelhecimento - revisão sistemática de literatura. Rev. Bras. Promoç. Saúde, Fortaleza, v. 3, n. 25, p. 364-373, 2012.

GONÇALVES D. A. R. Qualidade de vida nos idosos institucionalizados na Associação de Solidariedade Social de S. João de Negrilhos. 2014. 83f. Dissertação (Mestrado em Psicogerontologia Comunitária) - Instituto Politécnico de Beja, Beja, 2014.

LOBO, A. J. S.; SANTOS, L.; GOMES, S. Nível de dependência e qualidade de vida da população idosa. Rev. Bras. Enferm., Portugal, v. 6, n. 67, p. 913-918, 2014.

LOPES, M. A et al. Envelhecendo na percepção das pessoas longevas ativas e inativas fisicamente. Estud. Interdiscipl. Envelhec., Porto Alegre, v. 1, n. 19, p. 141-153, 2014.

MARI, F. R et al. The aging process and health: what middle-aged people think of the issue. Rev. Bras. Geriatr. Geronto, Rio de Janeiro, v. 1, n. 19, p. 35-44, 2016.

MARINHO, L. M et al. Degree of dependence of elderly residents in geriatric long-term care facilities in Montes Claros, MGa. Rev. Gaúcha Enferm., Minas Gerais, v. 1, n. 34, p. 104110, fev. 2013.

MARQUES, S. R. Tratamento fisioterapêutico na incontinência urinária em idosas. Revista Saúde Integrada, v. 9, n. 17, p. 110-116, 2016.

MENDES, R. S.; NOVELLI, M. M. P. C. Perfil cognitivo e funcional de idosos moradores de uma instituição de longa permanência para idosos. Cad. Ter. Ocup. Ufscar, São Carlos, v. 23, n. 4, p. 723-731, 2015.

ORTA, A. C. A. Contributo dos Centros de Dia para o bem-estar subjetivo dos idosos. 2014. 265f. Dissertação (Mestrado em Psicogerontologia Comunitária) - Instituto Politécnico de Beja. Beja, 2014.

PEREIRA, D. S.; NOGUEIRA, J. A. D.; SILVA, C. A. B. Qualidade de vida e situação de saúde de idosos: um estudo de base populacional no Sertão Central do Ceará. Rev. Bras. Geriatr. Gerontol., Rio de Janeiro, v. 4, n. 14, p. 893-908, 2015.

SANTANA, C. S.; BERNARDES, M. S.; MOLINA, A. M. T. B. Projetos de vida na velhice. Estud. Interdiscipl. Envelhec., Porto Alegre, v. 21, n. 1, p. 171-186, 2016.

SANTOS, I. $R$ et al. Análise dos parâmetros da marcha e do equilíbrio dos idosos após exercícios aeróbicos e terapêuticos. Arq. Ciênc. Saúde Unipar, Umuarama, v. 1, n. 20, p. 19-23, 2016.

SIQUEIRA et al. Efeito de um Programa de Fisioterapia Aquática e Capacidade Funcional de Idosos. Revista Saúde e Pesquisa, v. 10, n. 2, p. 331-338, maio/ago. 2017.

SPOSITO, $\mathrm{G}$ et al. A satisfação com a vida e a funcionalidade em idosos atendidos em um ambulatório de geriatria. Ciência \& Saúde Coletiva, São Paulo, v. 12, n. 18, p. 3.475-3.482, 2013.

SPOSITO, G.; NERI, A. L.; YASSUDA, M. S. Advanced Activities of Daily Living (AADLs) and cognitive performance in community-dwelling elderly persons: Data from the FIBRA Study - UNICAMP. Rev. Bras. Geriatr. Gerontol., Rio de Janeiro, v. 1, n. 19, p. 8-20, 2016.

TEIXEIRA, J. $\mathrm{S}$ et al. Envelhecimento e percepção corporal de idosos institucionalizados. Rev. Bras. Geriatr. Gerontol., Rio de Janeiro, v. 1, n. 15, p. 63-68, 2012. 